providers may have resulted in under-reporting of SLE signs and symptoms on this study. SLE ESRD patients should be carefully evaluated for subtle signs of active SLE.

REFERENCES:

[1] Mattos P, Santiago MB. Clin Rheumatol. 2012; 31:897-905.

[2] Stone JH. Lupus. 1998; 7:654-659.

[3] Krane NK, Burjak K, Archie M, O'Donovan R. Am J Kidney Dis. 1999; 33:872-879.

Disclosure of Interests: None declared

DOI: 10.1136/annrheumdis-2019-eular.4484

\section{FRI0253 RENAL TRANSPLANTATION IN LUPUS NEPHRITISVS NON-AUTOIMMUNE TRANSPLANTATION. LONG TERM FOLLOW-UP. STUDY FROM A SINGLE TERTIARY CENTER}

Lara Sánchez Bilbao ${ }^{1}$, Iñigo González-Mazón ${ }^{1}$, Marina de Cos-Gómez ${ }^{2}$, Belén Atienza-Mateo ${ }^{1}$, José Luis Martín-Varillas ${ }^{1}$, Monica Calderón-Goercke ${ }^{1}$, D. Prieto-Peña ${ }^{1}$, Juan Carlos Ruiz-San Millán², Miguel Á. González-Gay', Ricardo Blanco ${ }^{1} .{ }^{1}$ Rheumatology. Hospital Universitario Marqués de Valdecilla, IDIVAL., Santander, Spain; ${ }^{2}$ Nephrology. Hospital Universitario Marqués de Valdecilla, IDIVAL., Santander, Spain

Background: Lupus nephritis (LN) is a severe complication of systemic lupus erythematosus (SLE), affecting up to $30-40 \%$ of patients. Unfortunately, approximately $10-20 \%$ of $L N$ develop end stage renal disease (ESRD) and need replacement therapy. Renal transplantation may be a good option. However, concerns about LN recurrence after renal transplantation have been reported.

Objectives: In a series of patients with first renal transplantation due to LN our aim was to assess a) long-term post-transplant survival and, b) comparison of post-transplant survival with a control group due to a nonautoimmune nephropathy, the polycystic kidney disease (PCKD).

Methods: We study two groups of patients with first renal transplantation: a) LN and b) control group with PCKD. All these patients were transplanted in a single reference University Hospital. The main outcome variables were a) graft and patient survival up to 20 years and b) evolution of renal function (serum creatinine and proteinuria) in the first 5 years of follow-up. Cumulative survival rates after transplantation were estimated by the Kaplan-Meier method and compared between groups using the log-rank test. Mann-Whitney test was used to compare quantitative variables and $\mathrm{chi}^{2} /$ Fisher's exact test for qualitative variables.

Results: We included a total of 53 patients with renal transplant; a) LN group ( $n=21)$, b) PCKD group ( $n=32$ ). No significant differences at baseline were observed between the 2 groups regarding sex and cardiovascular risk factors. Significant differences were found in terms of age at kidney transplantation, with a mean of $39.80 \pm 11.27$ years in $\mathrm{LN}$ group and 46.59 \pm 5.01 years in the PCKD group $(p=0.004)$. Renal biopsy had been performed in 16 patients with LN: type II LN (25\%), type III (25\%) and type IV $(50 \%)$, (according to the World Health Organization and International Society of Nephrology/Renal Pathology Society classification). From 48 patients (of 53) in which a renal biopsy was performed during the firstyear post-transplant, rejection was found in 21 patients (43.7\%) without significant differences between the 2 groups $(p=0.444)$. The evolution of serum creatinine and proteinuria after renal transplantation is shown in TABLE-1. Regarding serum creatinine, significant differences were found in creatinine levels only at the 6 th month post-transplant $(p=0.032)$ with no differences in the following measurements. In LN group, 3 patients (14.3\%) developed a lupus flare: 2 cases presented as extrarenal disease and only 1 case with histological recurrence in the graft. No significant differences were found in terms of patient or graft survival between the two groups in 20 years of follow-up (Figures 1 and 2).

Conclusion: Despite concerns about LN recurrence after renal transplantation, data obtained in our sample indicate that this procedure as a safe alternative therapy for ESRD in this population and can provide a longterm survival.
TABLE 1. Evolution of creatinine and proteinuria levels after renal transplant in $L N$ and PCKD.

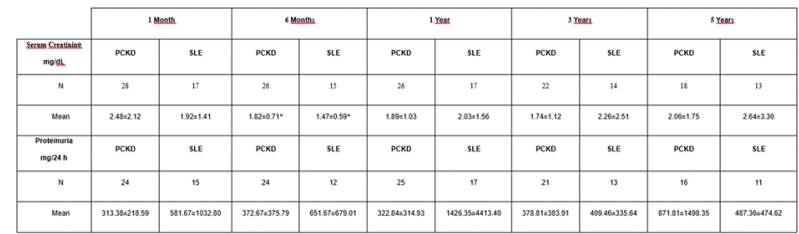

${ }^{*} p<0.05$

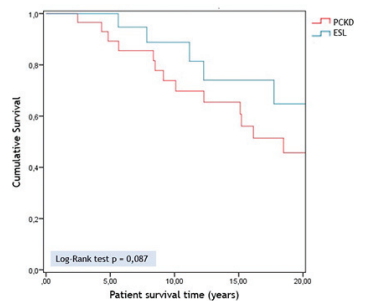

FIGURE 1. Patient survival

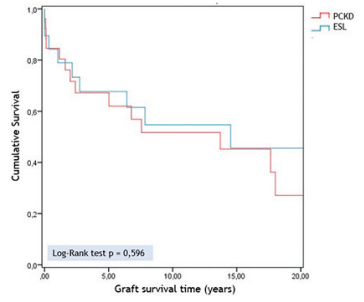

FIGURE 2. Graft survival

Disclosure of Interests: Lara Sánchez Bilbao: None declared, Iñigo González-Mazón: None declared, Marina de Cos-Gómez: None declared, Belén Atienza-Mateo: None declared, José Luis Martín-Varillas: None declared, Monica Calderón-Goercke: None declared, D. Prieto-Peña: None declared, Juan Carlos Ruiz-San Millán: None declared, Miguel Á. González-Gay: None declared, Ricardo Blanco Grant/research support from: Abbvie, MSD, and Roche, Consultant for: Abbvie, Pfizer, Roche, BristolMyers, Janssen, Speakers bureau: Abbvie, Pfizer, Roche, Bristol-Myers, Janssen

DOI: 10.1136/annrheumdis-2019-eular.2670

\section{FRI0254 COMBINED PANEL OF NINE TESTS HAS THE GREATEST SENSITIVITY BUT THE LOWEST SPECIFICITY TO DETECT ANTIPHOSPHOLIPID ANTIBODY SYNDROME IN PATIENTS WITH SYSTEMIC LUPUS ERYTHEMATOSUS}

Saika Sharmeen ${ }^{1}$, Katalin Banki ${ }^{2}$, Andras Perl ${ }^{1} .{ }^{1}$ State University of New York, Upstate Medical University, Medicine, Syracuse, United States of America; ${ }^{2}$ State University of New York, Upstate Medical University, Clinical Pathology, Syracuse, United States of America

Background: Antiphospholipid antibody syndrome (APS) is an autoimmune hypercoagulable state caused by antiphospholipid antibodies (aPL) which represent a diagnostic criterion and underlie significant comorbidities in patients with and without systemic lupus erythematosus (SLE). Although several tests exist for APS diagnosis, their utilization has been highly variable among laboratories and physicians.

Objectives: We have evaluated a panel of nine tests and conducted a retrospective study to determine their sensitivity and specificity for supporting the diagnosis of APS in SLE at our Institution between 2010 and 2018.

Methods: 1633 SLE patients, who satisfied the ACR criteria for a definitive diagnosis [1 2], were evaluated for the presence of APS as earlie described [3]. Lupus anticoagulants were assessed by Staclot LA hexagonal phase phospholipid neutralization assay (HPPNA; delta $<8$ seconds) Staclot diluted Russell viper venom test (dRVVT; $<1.2$ normalized ratio) 